\title{
Evaluasi Strategi Bersaing Diferensiasi PT Terminal Teluk Lamong pada Pelayanan Bongkar Muat Petikemas: Studi Banding Antar-Terminal Petikemas di Lingkungan Pelabuhan Tanjung Perak
}

\author{
Arief Budiman dan Bambang Tjahjadi \\ Universitas Airlangga \\ e-mail: ariefbudimen@gmail.com
}

\begin{abstract}
Port business (loading unloading container) give a positive impact for other industries related to control, arrange and develop logistics activities and material distribution. Port can be the best solution for reduce and speed up commodity distribution process. Purpose of this research is to evaluate the application of differentiation competitive strategies that have been applied so far in PT Terminal Teluk Lamong on the area of PT Pelabuhan tanjung Perak and give recommendation of that issues in order to improve the quality of container services in Tanjung Perak port environment. This research is using qualitative approach especially case study. Sample of this study is using a purposive sampling and interview with a key informan. The result of this research is strategy implementation in PT Terminal Teluk Lamong to improve container loading unloading performance by using high technology system, Go Green port concept and human resources that can easily adapt with company improvement. The recommendation is to maintain Go Green port concept consistently, and keep make an innovation that focus in giving the best service for the customer.
\end{abstract}

Keywords: differentiation, competition strategy, loading unloading service

\section{PENDAHULUAN}

Indonesia merupakan negara kepulauan yang dua pertiga wilayahnya adalah perairan dan terletak pada lokasi yang strategis karena berada di persinggahan rute perdagangan dunia. Sebagai negara kepulauan yang sebagian besar daerahnya adalah lautan, tak salah jika Indonesia disebut sebagai Negara Maritim (Asihra, 2018). Dengan sebutan Negara Maritim, dengan demikian Indonesia dituntut dapat mengikuti perkembangan dunia internasional dan menjadi Poros Maritim Dunia, yaitu dengan mengembangkan pelabuhan-pelabuhan yang besar serta mendorong investasi di bidang kemaritiman secara besar. Keberlanjutan pengembangan pelabuhan (Sustainability Port Development) tersebut menjadi hal yang sangat penting, mengingat hampir $80 \%$ total volume perdagangan dunia menggu- nakan transportasi laut, di mana sebanyak 70\% merupakan total nilai perdagangan dunia. Persentase volume sebesar $80 \%$ tersebut, diketahui bahwa Asia menguasai pangsa sebesar 40\% (muat/loaded) dan 60\% (bongkar/unloaded) (UNCTAD, 2015 dalam Ulfany, Wicaksono, dan Anwar, 2017).

Pada tahun 2014, pelabuhan di Indonesia dilaporkan memiliki Throughput 14,3 juta TEUs, capaian yang cukup tinggi jika dibandingkan 14 tahun lalu, dengan demikian mencerminkan adanya suatu tingkat pertumbuhan rata-rata $7,7 \%$. Hal ini sejalan dengan adanya peningkatan Throughput yang dialami Container PT Pelindo III, di mana meningkat sebanyak 2,4 juta pada tahun 2005 menjadi sekitar 4,3 juta TEUs pada tahun 2017, dengan peningkatan pertumbuhan Throughput kontainer 7,2\% per tahun. Berikut 
ini adalah arus petikemas PT Pelindo III periode tahun 2010-2015.

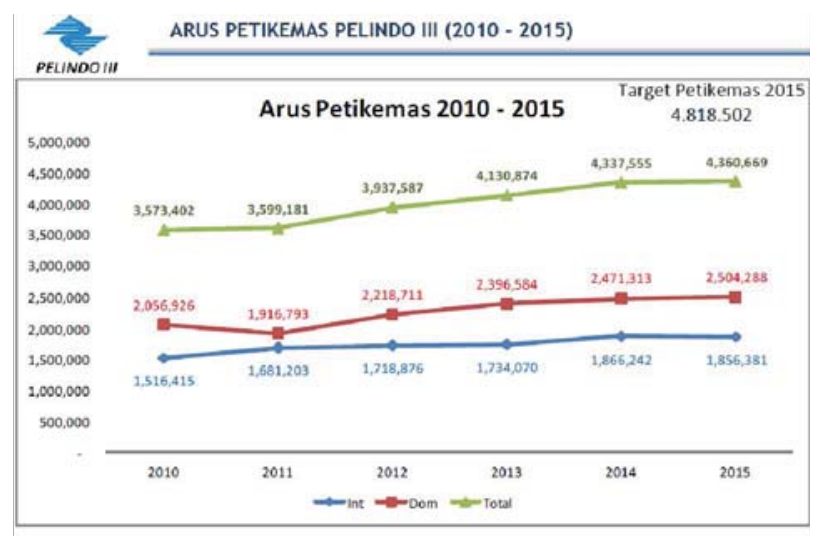

PT Terminal Teluk Lamong merupakan anak perusahaan PT Pelindo III yang dibangun sebagai pengembangan dari Pelabuhan Tanjung Perak, dilengkapi dengan peralatan ramah lingkungan dan semi-otomatis. PT Terminal Teluk Lamong berfungsi sebagai solusi terbaik untuk mengurangi kepadatan dan mempercepat proses distribusi arus barang terutama dari dan ke wilayah Indonesia Timur. PT Terminal Teluk Lamong melayani jasa Terminal Peti Kemas (bongkar muat kontainer) dan Curah Kering (Dry Bulk). Dengan adanya peralatan modern, PT Terminal Teluk Lamong diharapkan mampu mendorong dan meningkatkan perekonomian di Indonesia.

Terminal Teluk Lamong dibangun oleh Pelabuhan Indonesia III (Persero) dengan menerapkan konsep ramah lingkungan (Green Port) dan mengimplementasikan teknologi mutakhir, memakai alat bongkar muat dan truck berbahan bakar gas sehingga tidak menimbulkan polusi udara di sekitarnya, selain itu manajemen juga menanam ribuan pohon di sekitar Teluk Lamong sebagai penghijauan dan penunjang konsep green port, konsep ini dipilih agar Terminal Teluk Lamong mampu bersaing dengan terminal canggih di wilayah Tanjung Perak, Indonesia hingga negara lain.
Menurut proyeksi arus petikemas Tanjung Perak (Gambar 1.4), digambarkan bahwa ada kemungkinan kenaikan kapasitas sampai 8 juta sampai 9 juta TEU's pada tahun 2025. Dengan demikian, peluang usaha di bidang layanan jasa peti kemas diperkirakan akan terus mengalami peningkatan setiap tahunnya. Melihat peluang bisnis yang cukup menjanjikan, tentu saja hal ini tidak hanya PT Terminal Teluk Lamong saja yang akan memanfaatkan peluang tersebut, melainkan akan banyak pesaing (pemain lama dan pemain baru) yang akan bermain pada lahan bisnis yang sama.

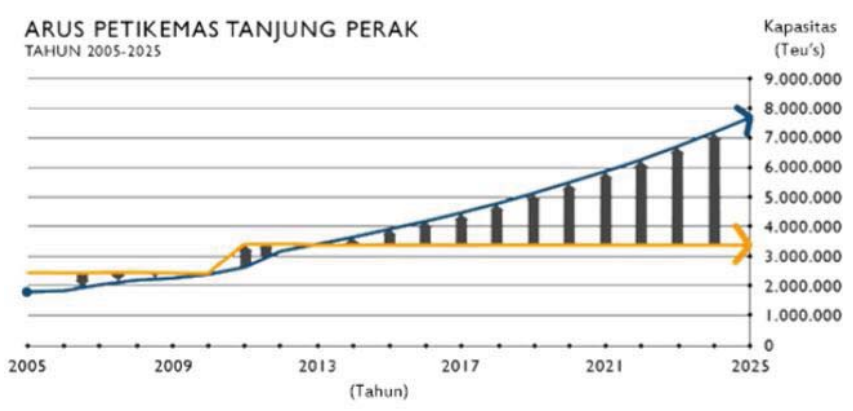

Untuk bertahan dalam persaingan bisnis ini, PT Terminal Teluk Lamong harus sigap dan tepat dalam menentukan strategi. Berdasarkan Gambar 1.6, terlihat adanya peningkatan bongkar muat petikemas PT Terminal Teluk Lamong selama empat tahun terakhir.

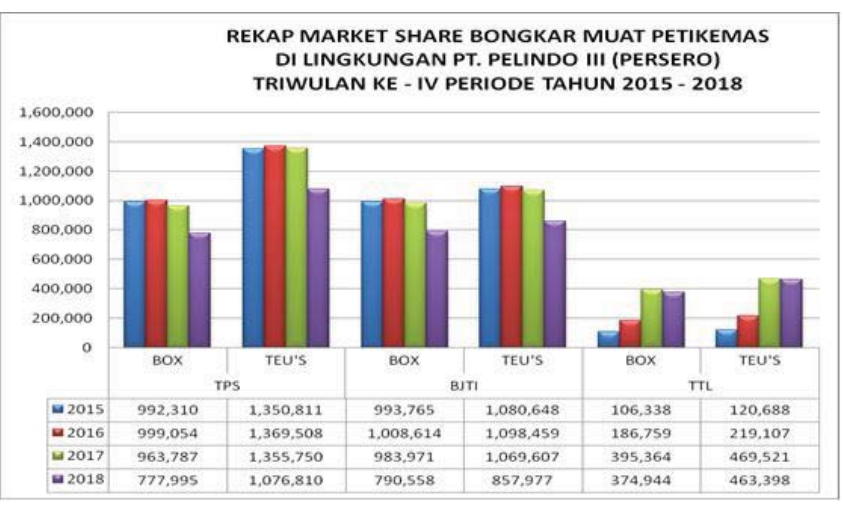

Namun jika dibandingkan dengan kompetitor lain perolehan bongkar muat petikemas PT Terminal Teluk Lamong sangat kecil sekalipun 
Arief Budiman \& Bambang Tjahjadi, Evaluasi Strategi Bersaing Diferensiasi PT Terminal Teluk Lamong pada Pelayanan Bongkar Muat Petikemas: Studi Banding Antar-Terminal Petikemas di Lingkungan Pelabuhan Tanjung Perak

mengalami peningkatan setiap tahunnya. Hal ini menjadi sangat penting untuk diperhatikan mengingat Market Share PT Terminal Teluk Lamong pada Lingkup Pelabuhan Tanjung Perak hanya sebesar $14 \%$, di mana Market Share terbesar dikuasai oleh PT Terminal Petikemas (Gambar 1.7). Peningkatan jumlah yang tidak signifikan setiap tahunnya menunjukkan adanya peluang bagi PT Terminal Teluk Lamong untuk bisa mengimbangi kompetitor.

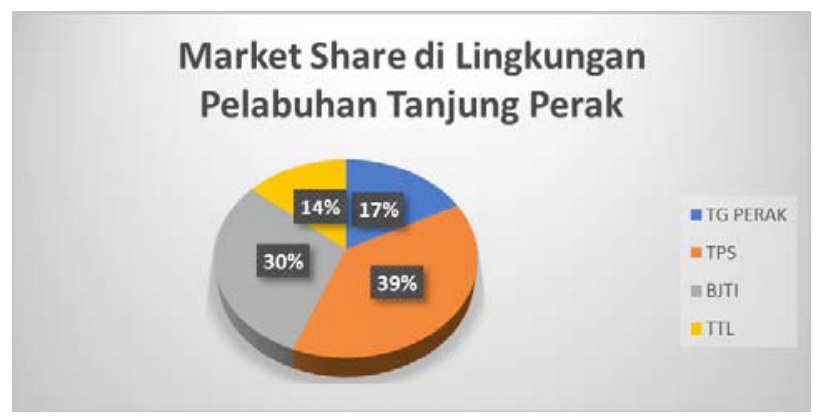

Dengan latar belakang yang telah dijelaskan, maka peneliti tertarik untuk menelaah lebih lanjut mengenai strategi bersaing PT Terminal Teluk Lamong dalam upaya bertahan dan memenangkan persaingan. Untuk itu, peneliti bermaksud mengajukan judul penelitian "Evaluasi Strategi Bersaing Diferensiasi PT Terminal Teluk Lamong pada Pelayanan Bongkar Muat Petikemas: Studi Banding Antar-Terminal Petikemas di Lingkungan Pelabuhan Tanjung Perak".

\section{TINJAUAN PUSTAKA}

\section{Strategi Bersaing}

Strategi menurut Griffin (2009) adalah rencana komprehensif untuk mencapai tujuan organisasi, sebaliknya manajemen strategi adalah cara untuk menanggapi peluang dan tantangan bisnis. Strategi yang efektif adalah strategi yang mendorong terciptanya keselarasan yang sempurna antara organisasi dengan lingkungannya dan dengan pencapaian tujuan strateginya. Sedangkan menurut Pearce dan Robinson (2008), strategi adalah rencana berskala besar dengan orientasi masa depan, guna berinteraksi dengan kondisi persaingan untuk mencapai tujuan perusahaan. Strategi mencerminkan pengetahuan perusahaan mengenai bagaimana, kapan, dan di mana perusahaan kan bersaing, dengan siapa perusahaan sebaiknya bersaing, dan untuk tujuan apa perusahaan harus bersaing (Lesal, 2015).

Strategi bersaing adalah pengembangan rencana mengenai bagaimana bisnis akan bersaing, apa yang seharusnya menjadi tujuan dan kebijakan yang diperlukan untuk mencapai tujuan tersebut (Porter, 2001). Sedangkan menurut Robbins dan Coulter (2010), strategi bersaing adalah tentang bagaimana organisasi akan bersaing dalam bisnisnya. Bagi organisasi kecil yang hanya berkecimpung dalam satu lini bisnis atau organisasi besar yang belum diversifikasi dalam berbagai produk atau pasar, strategi kompetitif menggambarkan bagaimana organisasi tersebut akan bersaing di pasar primer atau utamanya, namun bagi organisasi yang berkecimpung dalam berbagai bisnis, setiap bisnis mempunyai strategi kompetitifnya sendiri yang mendefinisikan keunggulan kompetitifnya, produk atau jasa yang ditawarkan, pelanggan yang ingin dijangkaunya, dan kesukaannya. Inti dari strategi bersaing yaitu bagaimana sebuah organisasi melakukan upaya-upaya untuk mendapatkan keunggulan kompetitif yang berkesinambungan. Alternatif strategi bersaing yang tepat dan dapat diterapkan pada sebuah organisasi didasarkan pada keunggulan kompetitif yang dapat dikembangkan oleh organisasi tersebut (Odeth, 2017).

\section{Strategi Generik dan Keunggulan Bersaing}

Keunggulan bersaing memiliki dua arti yang berbeda tetapi saling berhubungan. Ketatnya 
persaingan menyebabkan perusahaan berusaha untuk memenangkan persaingan dengan cara menerapkan strategi bersaing yang tepat sehingga dapat melaksanakan serta mewujudkan tujuantujuan sesuai dengan apa yang diharapkan. Keunggulan kompetitif, termasuk bagaimana mendapatkan dan mempertahankannya, merupakan konsep kunci dalam manajemen strategis. Keunggulan kompetitif akan timbul dengan cara memiliki sesuatu yang tidak dimiliki oleh pesaing lain. Keunggulan kompetitif adalah strategi bersaing sesuatu yang dirancang untuk dieksploitasi oleh suatu organisasi (Coulter, 2003 dalam Kuncoro, 2006).

\section{Segmentasi, Targeting, dan Positioning}

Pengertian segmentasi pasar menurut Kotler \& Armstrong (2004) adalah membagi sebuah pasar ke dalam kelompok-kelompok pembeli yang khas berdasarkan kebutuhan, karakteristik, atau perilaku yang mungkin membutuhkan produk atau bauran pemasaran yang terpisah. Adapun menurut Assauri (2004), segmentasi pasar merupakan suatu proses membagi-bagi suatu pasar yang heterogen ke dalam kelompok-kelompok pembeli atau konsumen yang memiliki ciri-ciri/sifat yang homogen dan dapat berarti bagi perusahaan.

Segmentasi Pasar adalah kegiatan membagibagi pasar yang bersifat heterogen dari suatu produk ke dalam satuan-satuan pasar (segmen pasar) yang bersifat homogen. Berdasarkan definisi di atas diketahui bahwa pasar suatu produk tidaklah homogen, akan tetapi pada kenyataannya adalah heterogen. Pada dasarnya segmentasi pasar adalah suatu strategi yang didasarkan pada falsafah manajemen pemasaran yang orientasinya adalah konsumen. Dengan melaksanakan segmentasi pasar, kegiatan pemasaran dapat dilakukan lebih terarah dan sumber daya yang dimiliki perusahaan dapat digunakan secara lebih efektif dan efisien dalam rangka memberikan kepuasan bagi konsumen.

\section{Targeting}

Targeting adalah merupakan kegiatan yang berisi dan menilai serta memilih satu atau lebih segmen pasar yang akan dimasuki oleh suatu perusahaan. Apabila perusahaan ingin menentukan segmen pasar mana yang akan dimasukinya, maka langkah yang pertama adalah menghitung dan menilai potensi profit dari berbagai segmen yang ada tadi. Maka dalam hal ini, pemasar harus mengerti betul tentang teknik-teknik dalam mengukur potensi pasar dan meramalkan permintaan pada masa yang akan datang. Teknikteknik yang dipergunakan ini sangat bermanfaat dalam memilih pasar sasaran, sehingga pemasar dapat menghindarkan kesalahan-kesalahan yang bakal terjadi, atau paling tidak menguranginya sekecil mungkin dalam praktiknya. Maka untuk tujuan tersebut perusahaan harus membagi-bagi pasar menjadi segmen-segmen pasar utama, setiap segmen pasar kemudian dievaluasi, dipilih dan diterapkan segmen tertentu sebagai sasaran.

\section{Positioning}

Penempatan produk mencakup kegiatan merumuskan penempatan produk dalam persaingan dan menetapkan bauran pemasaran yang terperinci. Penempatan posisi adalah strategi yang sangat penting dalam membangun sebuah merek. Dalam pasar yang tingkat persaingannya tinggi, penempatan posisi memberikan diferensiasi yang diperlukan untuk menjawab pertanyaan yang kritis, mengapa berbeda dengan pesaing, dan mengapa lebih baik dari pesaing (Susanto dan Wijanarko, 2004 dalam Faqih, 2008).

Menurut pendapat Kotler dan Keller (2007), penetapan posisi (positioning) adalah 
Arief Budiman \& Bambang Tjahjadi, Evaluasi Strategi Bersaing Diferensiasi PT Terminal Teluk Lamong pada Pelayanan Bongkar Muat Petikemas: Studi Banding Antar-Terminal Petikemas di Lingkungan Pelabuhan Tanjung Perak

tindakan merancang tawaran dan citra perusahaan sehingga menempati posisi yang khas (dibandingkan para pesaing) di dalam benak pelanggan sasarannya. Tujuannya adalah menempatkan merek dalam pikiran konsumen untuk memaksimalkan potensi manfaat perusahaan.

\section{Value Chain}

Menurut Porter yang dikutip oleh David (2012), bisnis sebuah perusahaan paling baik dideskripsikan sebagai rantai nilai (Value Chain), di mana total pendapatan dikurangi total biaya semua aktivitas yang dilakukan untuk mengembangkan dan memasarkan produk atau jasa yang dihasilkan nilai. Semua perusahaan di suatu industri memiliki rantai nilai yang serupa, yang mencakup berbagai aktivitas seperti memperoleh bahan mentah, merancang produk, membangun fasilitas manufaktur, mengembangkan perjanjian kerjasama, dan menyediakan layanan konsumen. Sebuah perusahaan akan meraih keuntungan jika total pendapatan melampaui total biaya yang ditimbulkan dari penciptaan dan pengiriman produk atau jasa. Menurut David (2012), analisis rantai nilai (Value Chain analysis-VCA) mengacu pada proses yang dengannya perusahaan menentukan biaya yang terkait dengan aktivitas organisasional dari pembelian bahan mentah sampai produksi dan pemasaran produk tersebut. Sedangkan menurut Pearce dan Robinson (2007), rantai nilai merupakan sebuah perspektif di mana bisnis dipandang sebagai rantai kegiatan dalam mengubah input menjadi output yang memberikan nilai kepada pelanggan. Sedangkan analisis rantai nilai adalah sebuah analisis yang mencoba untuk memahami bagaimana suatu bisnis dapat menciptakan nilai bagi pelanggan (customer value) dengan menguji kontribusi dari kegiatan yang berbeda dalam suatu perusahaan.

\section{Diferensiasi}

Diferensiasi adalah suatu cara merancang perbedaan yang berarti untuk membedakan penawaran perusahaan dari penawaran pesaingnya (Kotler dan Susanto, 2001). Strategi diferensiasi adalah suatu strategi yang dapat memelihara loyalitas pelanggan di mana dengan menggunakan strategi diferensiasi, pelanggan mendapat nilai lebih dibandingkan dengan produk lainnya. Perusahaan akan melakukan diferensiasi terhadap para pesaingnya apabila perusahaan tersebut telah berhasil menampilkan keunikan yang dinilai penting oleh pelanggan, selain dengan penawaran harga yang rendah di mana telah banyak dilakukan oleh perusahaan atau pesaing (Delmas, 2000). Padahal diferensiasi dapat dilakukan dengan penawaran harga tinggi, sehingga perusahaan yang melakukan diferensiasi harus merancang serangkaian perbedaan yang berarti untuk membedakan tawaran yang diberikan perusahaan dengan tawaran pesaing (Tampi, 2015).

\section{PERUMUSAN MASALAH}

Berdasarkan uraian latar belakang permasalahan di dalam penelitian, maka pertanyaan penelitian yang akan dijawab melalui penelitian ini adalah sebagai berikut.

1. Apakah penerapan strategi bersaing diferensiasi PT Terminal Teluk Lamong pada pelayanan bongkar muat petikemas di lingkungan Pelabuhan Tanjung Perak dapat menunjang peningkatan kinerja bongkar muat petikemas?

2. Rekomendasi apakah yang dapat diberikan pada PT Terminal Teluk Lamong dari Hasil Penerapan Penerapan Strategi Bersaing Diferensiasi PT Terminal Teluk Lamong pada Pelayanan Bongkar Muat Petikemas di Lingkungan Pelabuhan Tanjung Perak? 


\section{METODE PENELITIAN}

Penelitian ini digunakan pendekatan studi kasus sebagai bagian dari penelitian kualitatif. Studi kasus berfokus pada spesifikasi kasus dalam suatu kejadian baik itu yang mencakup individu, kelompok budaya, ataupun suatu potret kehidupan. Creswell (2010) mengatakan bahwa studi kasus merupakan strategi penelitian di mana di dalamnya peneliti menyelidiki secara cermat suatu program, peristiwa, aktivitas, proses, atau sekelompok individu. Studi kasus adalah sebuah penyelidikan empiris yang menginvestigasi fenomena kontemporer dalam konteks kehidupan nyata, khususnya ketika batas antara fenomena dan konteks tidak begitu jelas (Yin, 2011).

\section{Sampel dan Teknik Pengambilan Sampel}

Sampel yang digunakan dalam penelitian ini adalah key informan (informan kunci) yaitu orang-orang yang sangat memahami organisasi dan memiliki kepentingan sesuai dengan informasi yang dibutuhkan. Penentuan informan kunci ditentukan menggunakan purposive sampling. Pada penelitian ini, akan dilakukan interview dengan beberapa key informan berdasarkan struktur organisasi PT Terminal Teluk Lamong, yaitu Corporate Planning o Communication Department Head, Terminal Operation Department Head, Information Communication \& Technology Department Head, Commercial and Business Development Head, Human Capital Department Head, Staff Abli Head Office Pelindo 3 dan Pelaku Usaha/Pengguna Jasa di Lingkungan Terminal Teluk Lamong.

\section{Lokasi Penelitian}

Penelitian ini dilakukan di PT Terminal Teluk Lamong.

\section{Teknik Analisis}

Pengolahan data penelitian dapat dilakukan dengan beberapa tahapan. Pertama, reduksi data (data reduction), dalam tahap ini peneliti melakukan pemilihan, dan pemusatan perhatian untuk penyederhanaan, abstraksi, dan transformasi data kasar yang diperoleh. Kedua, penyajian data (data display), peneliti mengembangkan sebuah deskripsi informasi tersusun untuk menarik kesimpulan dan pengambilan tindakan. Display data atau penyajian data yang lazim digunakan pada langkah ini adalah dalam bentuk teks naratif. Serta yang terakhir adalah Penarikan kesimpulan dan verifikasi (conclusion drawing and verification).

\section{ANALISIS DAN PEMBAHASAN HASIL PENELITIAN}

\section{PT Terminal Teluk Lamong Berdasarkan Temu- an Peneliti}

Peneliti akan membahas menggambarkan awal mula berdirinya PT Terminal Teluk Lamong berdasarkan hasil observasi dan wawancara. Sekilas cerita mengenai PT Terminal Teluk Lamong, yang diketahui sebagai anak perusahaan PT Pelabuhan Indonesia 3 dengan bidang usaha jasa bongkar muat petikemas dan jasa dermaga. Menurut informasi yang didapatkan bahwa perusahaan bidang jasa bongkar muat petikemas sebelum PT Terminal Teluk Lamong di antaranya adalah PT Berlian Jasa Terminal Indonesia (BJTI) dan PT Terminal Petikemas Surabaya (TPS) di mana keduanya merupakan anak perusahaan PT Pelabuhan Indonesia 3 yang lebih dulu dibangun di kawasan Tanjung Perak. Adanya kendala kondisi kedalaman dermaga yang tidak memungkinkan bagi BJTI dan TPS jika tetap memaksakan untuk beroperasi, mengakibatkan manajemen memikirkan solusi yang terbaik agar usaha yang telah dibangun dapat tetap berjalan. 
Arief Budiman \& Bambang Tjahjadi, Evaluasi Strategi Bersaing Diferensiasi PT Terminal Teluk Lamong pada Pelayanan Bongkar Muat Petikemas: Studi Banding Antar-Terminal Petikemas di Lingkungan Pelabuhan Tanjung Perak

PT Pelabuhan Indonesia 3 melihat peluang tempat baru di wilayah Teluk Lamong sebagai salah satu solusi bagi pelanggan yang memerlukan jasa bongkar muat. Pertimbangan lain yang didapatkan dari key informan penelitian bahwa BJTI dan TPS yang merupakan anak perusahaan PT Pelabuhan Indonesia 3 tidak dapat menambah atau memaksimalkan fasilitas pelayanan dikarenakan kondisi tempat di wilayah Tanjung Perak sudah tidak memungkinkan untuk dilakukan pengembangan. Selain itu, pembaharuan teknologi tidak dapat dilakukan mengingat sebagian saham TPS dimiliki asing, sehingga menjadikan manajemen untuk lebih memilih peluang membangun serta mengembangkan pelayanan jasa bongkar muat di wilayah baru yang murni tanpa kepemilikan asing.

\begin{abstract}
...." Pesaing tidak mengambil peluang tersebut, karena permasalahannya sama yaitu panjang dermaga, mereka pesaing tidak bisa memperpanjang dermaga dikarenakan sempitnya lahan, sedangkan di TTL lahan masih tersedia. TTL tidak pernah mengatakan dua dermaga tambatan jadi masih fleksibel dalam pengaturan tambatan, panjang dermaga 500 meter bisa dipakai dua kapal dan bisa dipakai satu kapal tergantung panjang kapal. Sedangkan pesaing (TPS dan BJTI) ada statement empat dermaga tambatan dengan panjang 1000 meter sehingga harus ada fiks empat kapal. Di dermaga pesaing, jika ada panjang kapal lebih besar maka mereka tidak menerima, karena ada space yang pasti kosong dan menurut mereka itu bisa merugikan pendapatan perusahaan, pelanggan pesaing lebih banyak sehingga aka nada antrean jika empat tambatan hanya diisi dua sampai tiga kapal saja..." (key informan 2).
\end{abstract}

\section{Segmentasi}

Berbicara mengenai segmentasi, PT Terminal Teluk Lamong secara tidak langsung menetapkan segmen pasar yang sama dengan kompetitor yaitu Segmentasi atas dasar Geografis. Kembali pada sekilas cerita awal mula berdirinya PT
Terminal Teluk Lamong di mana usaha ini dibangun sebagai solusi alternatif lain jasa bongkar muat bagi pelanggan yang disebabkan kondisi jasa bongkar muat PT BJTI dan PT TPS sudah tidak memungkinkan untuk dilakukan pengembangan karena kondisi internal dan lingkungan tidak mendukung pembaharuan. Segmentasi pasar ini dilakukan dengan cara membagi pasar ke dalam unit-unit geografis seperti negara, provinsi, kabupaten, kota, desa, dan lain sebagainya.

\section{Targeting}

Targeting adalah merupakan kegiatan yang berisi dan menilai serta memilih satu atau lebih segmen pasar yang akan dimasuki oleh suatu perusahaan. Untuk tujuan tersebut perusahaan harus membagi-bagi pasar menjadi segmen-segmen pasar utama, setiap segmen pasar kemudian dievaluasi, dipilih dan diterapkan segmen tertentu sebagai sasaran. Berdasarkan segmentasi tersebut, PT Terminal Teluk Lamong menetapkan sasaran pada perusahaan-perusahaan logistik yang ada di Indonesia. Namun demikian jalur bongkar muat petikemas tidak hanya domestik melainkan jalur internasional. Pemilihan tersebut berdasarkan adanya peluang bisnis serta belum banyaknya perusahaan jasa petikemas atau bongkar muat yang ada di Indonesia serta Indonesia berada di wilayah Maritim ASEAN.

\section{Positioning}

Dalam hal ini PT Terminal Teluk Lamong menempatkan posisi dalam pikiran konsumen sebagai pendatang baru yang hadir dengan memberikan pelayanan prima yang didukung dengan teknologi tinggi. Selain itu konsep after sales services menjadi salah satu strategi pada internal business process. Dengan menjaga hubungan baik dengan pelanggan diharapkan PT Terminal 


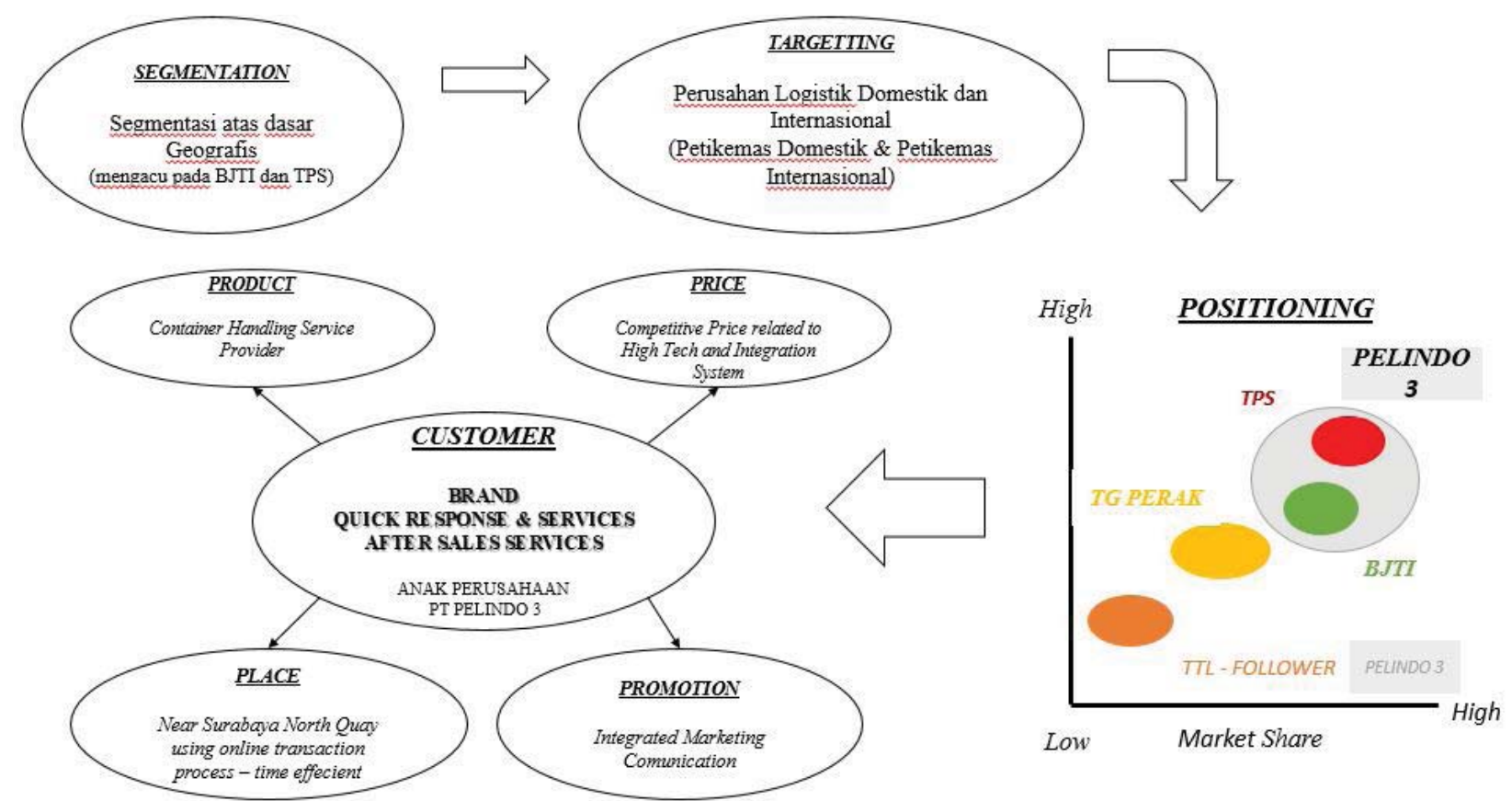

Teluk Lamong dapat lebih dekat dan mengerti apa yang menjadi kebutuhan pelanggan.

\section{Value Chain PT Terminal Teluk Lamong}

Berikut ini merupakan gambaran konsep value chain PT Terminal Teluk Lamong berdasarkan data sekunder dan hasil observasi.

\section{Aktivitas Primer (Primary Activities)}

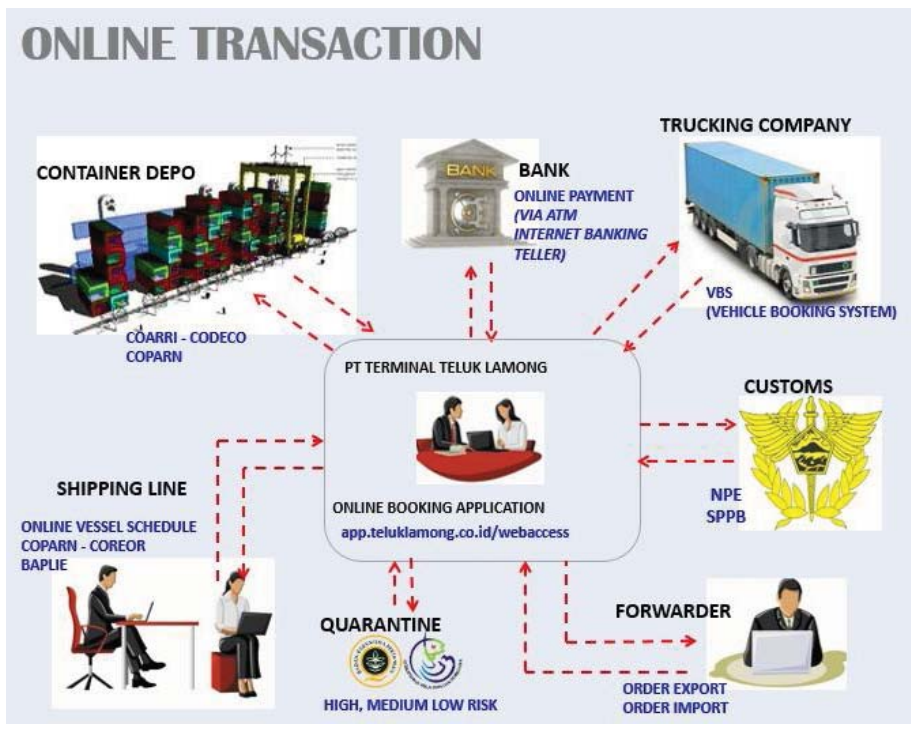

2. Aktivitas Sekunder (Support Activities)

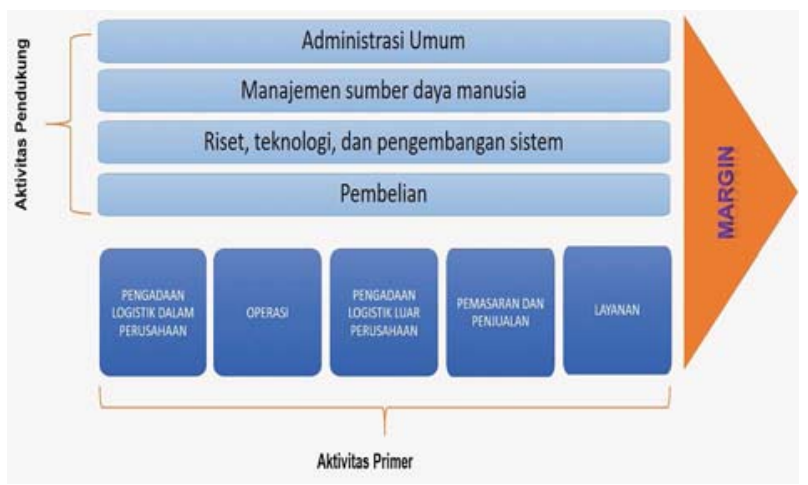

Strategi Diferensiasi PT Terminal Teluk Lamong

Menurut hasil wawancara bahwasanya strategi diferensiasi PT Terminal Teluk Lamong di antaranya adalah konsep transaksi full online yang terintegrasi, pelayanan automasi dan konsep Go Green Port. Konsep Go Green Port yang diterapkan perusahaan berfungsi sebagai terminal bongkar muat petikemas yang ramah lingkungan di support dengan teknologi yang canggih. Konsep inilah yang menjadikan PT Terminal Teluk Lamong dapat beroperasi dan mengimbangi kompetitor dalam hal ini pemain lama 
Arief Budiman \& Bambang Tjahjadi, Evaluasi Strategi Bersaing Diferensiasi PT Terminal Teluk Lamong pada Pelayanan Bongkar Muat Petikemas: Studi Banding Antar-Terminal Petikemas di Lingkungan Pelabuhan Tanjung Perak

yang telah lebih dulu bergerak di bidang pelayanan petikemas. Pernyataan tersebut disimpulkan berdasarkan key informan 2 dan key informan 4.

... 'pada saat TTL didirikan konsepnya ialah transaksi full online dan sistem terintegrasi secara online dengan semua stockholder, yang kedua adalah pelayanannya automasi, yang ketiga TTL ini adalah green port, maka tiga konsep ini yang harus dijalankan. Konsep ini belum banyak pelanggan yg tahu'... (key informan 2).

... "teluk lamong itu adalah pelabuhan yang relative baru, baik dari infrastruktur dan peralatan operasi dalam mendukung kegiatan ini paling baru dan paling modern berada posisi empat di dunia dalam infrastruktur di Teluk Lamong dengan demikian jelas dari awalnya pemikiran strategi yang berbeda sudah terlihat pemikiran manajemen dahulu, kita lihat dari PT TPS bekerja sama dengan Dubai Port dan stakeholder itu menggunakan infrastruktur masih menggunakan teknologi yang cenderung lama kalau teknologi yang terbaru hanya di TTL dan lebih mengarah ke GO GREEN PORT" ... (key informan 4).

Hasil wawancara lain yang mendukung pendapat Aaker dalam Ferdinand (2003) bahwa setiap tahun sejak mulai berdiri jumlah pelanggan PT Terminal Teluk Lamong terus meningkat, walaupun masih di bawah pemegang market share terbesar di area Pelabuhan Tanjung Perak namun sebagai pendatang baru kemampuan melihat peluang dan penetapan strategi perusahaan tidak bisa diragukan lagi. Namun, menurut salah satu key informan mengatakan bahwa market share akan tumbuh jika industri manufaktur, export import tumbuh dengan baik kemudian pengiriman antar pulau berkembang maka market share akan meningkat, dan sebaliknya ketika pertumbuhan industri tersebut stagnan atau naik sedikit tidak akan bisa meningkatkan kemampuan handling secara optimal. Dengan kata bahwasanya peningkatan market share menjadi sulit meningkat jika tidak terjadi pertumbuhan ekonomi dan perkembangan industri yang terkait dengan jasa pelabuhan.

\section{SIMPULAN DAN SARAN}

\section{Simpulan}

Dari hasil penelitian dapat diambil kesimpulan sebagai berikut.

1. Berdasarkan hasil penelitian diketahui bahwa sejauh ini penerapan strategi PT Terminal Teluk Lamong dapat menunjang peningkatan kinerja bongkar muat petikemas dengan pemanfaatan high technology system, konsep Go Green Port serta didukung sumber daya manusia yang disiapkan untuk menunjang setiap perubahan yang dilakukan perusahaan. Strategi diferensiasi PT Terminal Teluk Lamong sesuai dengan RJPP yang telah disepakati dan dilakukan dengan baik di mana salah satu indikator penilaian yang dapat dilihat dengan meningkatnya market share. Terlepas dari image anak perusahaan PT Pelindo III, PT Terminal Teluk Lamong dapat menjalankan bisnisnya dengan progress yang meningkat setiap tahunnya. Keunggulan lain dari PT Terminal Teluk Lamong adalah cara melihat peluang dari kompetitor, pelayanan 24 jam secara online menjadi keunggulan tersendiri bagi PT Terminal Teluk Lamong, yang mana hal ini belum dilakukan oleh kompetitor lain. Kesigapan online customer service 24 jam patut dipertahankan, karena menjadi penilaian tersendiri bagi pelanggan. Hal ini dapat dilihat dengan adanya peningkatan jumlah pelanggan yang disertai dengan perbaikan sistem, peningkatan fasilitas, dan pelayanan prima (fokus pada totalitas pelayanan yang terintegrasi).

2. Konsisten mempertahankan konsep strategi Go Green Port yang diimbangi dengan pem- 
baharuan teknologi yang canggih secara berkesinambungan serta memaksimalkan dan mengembangkan sumber daya manusia pilihan untuk menunjang operasional perusahaan, maka ketiga elemen tersebut akan tetap menjadi strategi pilihan yang tepat bagi perusahaan, Terus berinovasi dengan fokus memberikan pelayanan prima kepada pelanggan dan Berbicara mengenai strategi, alangkah lebih baik jika sudah tidak lagi mengedepankan persaingan namun bekerja sama berkolaborasi untuk memaksimalkan pelayanan bongkar muat dengan kompetitor serta Performance management system yang ada digunakan sebagai media evaluasi dan dasar untuk perbaikan secara berkelanjutan.

\section{Saran}

Penelitian ini membuka peluang bagi peneliti berikutnya yang berminat pada manajemen strategis dan manajemen pemasaran. Hal lain yang dapat dilakukan di antaranya dapat meneliti atau mengevaluasi implementasi strategi green port pada PT Terminal Teluk Lamong dan mengevaluasi penetapan segmentasi, targeting, dan positioning strategi pemasaran PT Terminal Teluk Lamong.

\section{DAFTAR RUJUKAN}

Asihra, R.R. 2018. Strategi PT Pelabuhan Indonesia (Pelindo) I Persero dalam Implementasi Pelayanan Jasa Bongkar Muat Barang di Pelabuhan Belawan. Program Studi Ilmu Administrasi Publik Fakultas Ilmu Sosial dan Politik Universitas Sumatera Utara Medan.

Bungin, B. 2007. Penelitian Kualitatif: Komunikasi, Ekonomi, Kebijakan Publik, dan Ilmu Sosial lainnya. Jakarta: Putra Grafika.
Creswell, J.W. 2010. Research Design: Pendekatan Kualitatif, Kuantitatif, dan Mixed. Yogyakarta: PT Pustaka Pelajar.

Damanik, S. 2012. Strategi Bersaing 'Low Cost Carrier' PT Merpati Nusantara Airlines. Program Magister Manajemen Fakultas Ekonomi dan Bisnis Universitas Airlangga Surabaya.

Griffin, J. 2009. Customer Loyalty: How to Learn it, How to Keep it. Jakarta: Erlangga Gurning et al. 2007. Manajemen Bisnis Pelabuhan. Surabaya: PT Andhika Prasetya Ekawahana.

Hermanto, A.W. 2008. Analisis Tingkat Kepuasan Konsumen Terhadap Pelayanan Terminal Peti Kemas Semarang. Magister Teknik Sipil Program Pasca Sarjana, Universitas Diponegoro Semarang.

Hill, C.W.L. dan Jones, G.R. 2008. Strategic Management an Integrated Approach. Mason, Ohio: South-Western Cengage Learning.

Istijanto. 2005. Riset Sumber Daya Manusia. Jakarta: Gramedia Pustaka Utama.

Kramadibrata, S. 2002. Perencanaan Pelabuhan. Bandung: Institut Teknik Bandung.

Kuncoro, M. 2012. Metode Riset untuk Bisnis dan Ekonomi. Jakarta: Penerbit Erlangga. Kuntjoroadi, W. dan Safitri, N. 2009. Analisis Strategi Bersaing dalam Persaingan Usaha Penerbangan Komersial. Jurnal Ilmu Administrasi dan Organisasi. Vol. 16, No. 1, Hlm. 45-52.

Lapod, J. 2016. Analisis Penentuan Strategi dalam Lingkungan Bisnis yang Kompetitif Studi Kasus pada PT Pelindo IV (Persero). Jurnal Riset Bisnis dan Manajemen, Vol. 4, No.1, Hlm. 33-48.

Lesal, I. 2015. Analisis Internal dan Eksternal pada CV Gading Mas Surya Sidoarjo 
Arief Budiman \& Bambang Tjahjadi, Evaluasi Strategi Bersaing Diferensiasi PT Terminal Teluk Lamong pada Pelayanan Bongkar Muat Petikemas: Studi Banding Antar-Terminal Petikemas di Lingkungan Pelabuhan Tanjung Perak

dalam Rangka Strategi Bersaing. Jurnal AGORA Vol. 03, No 02, Hlm. 148-157. Moleong, L.J. 2012. Metodologi Penelitian Kualitatif. Bandung: PT Remaja Rosdakarya. Odeth, S. 2017. Analisis Strategi Bersaing Usaha Layanan Transportasi Online (Studi pada Indotiki di Kota Medan). Program Studi Ilmu Administrasi Bisnis Fakultas Ilmu Sosial dan Ilmu Politik Universitas Sumatera Utara Medan.

Pearce II, J.A. dan Robinson, R.B.Jr. 2008. Manajemen Strategis Edisi ke-10. Jakarta: Salemba Empat.

Pitoy, C.V., Tumbel, Altje, dan Tielung, M. 2016. Analisis Strategi Bersaing dalam Persaingan Usaha Bisnis Document Solution (Studi Kasus pada PT Astragraphia, Tbk. Manado). Jurnal Berkala Ilmiah Efisiensi, Vol. 16, No. 03, Hlm. 302-312.

Porter, M.E. 2001. Strategi Bersaing, Teknik Menganalisis Industri, dan Pesaing. Jakarta: Erlangga.

Robbins, S.P. dan Coulter, M. 2010. Manajemen Edisi Kesepuluh. Jakarta: Erlangga.

Rothaermel, F.T. 2013. Strategic Management: Concepts and Cases. New York: McGrawHill Irwin.

Rusly, C.O. dan Indriyani, R. 2013. Pengelolaan dan Pengembangan Usaha pada PT Sariadi Wahana Jasa Di Surabaya. Jurnal AGORA, Vol. 01, No. 01.

Salim, A. 2006. Teori dan Paradigma Penelitian Sosial. Yogyakarta: Tiara Wacana.
Satori, D. dan Komariah, A. 2011. Metode Penelitian Kualitatif. Bandung: Alfabeta. Supriyono. 2010. Analisis Kinerja Terminal Petikemas di Pelabuhan Tanjung Perak Surabaya. Universitas Diponegoro Semarang.

Suryana. 2006. Kewirausahaan Pedoman Praktis: Kiat dan Proses Menuju Sukses Edisi Ketiga. Jakarta: Penerbit Salemba.

Tampi, N.H.R. 2015. Analisis Strategi Diferensiasi Produk, Diferensiasi Layanan dan Diferensiasi Citra Terhadap Keunggulan Bersaing dan Kinerja Pemasaran (Studi pada PT Telkomsel Grapari Manado). Jurnal EMBA, Vol. 3, No. 4, Hlm. 68-81.

Triatmodjo, B. 2009. Perencanaan Pelabuhan. Yogyakarta: Beta Offset.

Ulfany, W. dan Anwar. 2017. Kajian Kinerja Pelayanan General Cargo Terminal Jamrud di Pelabuhan Tanjung Perak Surabaya. Jurnal Rekayasa Sipil, Vol. 11, No. 03, Hlm. 245-252.

Vredenbregt, J. 1980. Metode Penelitian Kualitatif. Jakarta: Van Hove.

Wahono, D. 2015. Terminal Petikemas pada Pelabuhan Internasional Pantai Kijing di Kecamatan Sungai Kunyit Kabupaten Pontianak. Jurnal Online Mahasiswa Arsitektur Universitas Tanjungpura, Vol. 03, No. 01, Hlm. 37-55.

Yin, R.K. 2011. Studi Kasus: Desain dan Metode. Jakarta: Rajagrafindo Persada.

Zyman, S. 2000. The End of Marketing as We Know it. Jakarta: PT Gramedia Pustaka Utama. 